\title{
Use of exercise tests in assessment of the functional result of aortocoronary bypass surgery
}

\author{
I Y LUKSIC, J A RAFFO, D A S G MARY, D A WATSON, P B DEVERALL, \\ AND R J LINDEN \\ From the Department of Cardiovascular Studies, University of Leeds, and Department of \\ Medical Cardiology, Eastern and Western Districts, Leeds Area Health Authority, Leeds
}

ABSTRACT The value of an objective exercise test for the assessment of the functional results of 0 aortocoronary bypass was investigated in 19 patients who were studied before and six months after the operation. For positive tests the end point was defined as a net ST segment depression $\subseteq$ of $0.1 \mathrm{mv} 80 \mathrm{~ms}$ after the J point of the ECG. For negative tests the end point was $85 \%$ of the age-predicted maximal heart rate response. One patient who was not able to attain either of $\vec{\oplus}$ these points after the operation was excluded. In the remaining 18 patients three indices were $\stackrel{\infty}{-}$ used in the analysis. First, the heart rate (HR) and the product of heart rate and systolic blood ${ }_{0}$ pressure (RPP) were measured at the defined level of ST segment depression during positive exercise tests to yield HR/ST and RPP/ST threshold respectively. Second, the HR and RPP were measured at the end point of the negative tests. Third, the duration of exercise till the end $\stackrel{\circ}{\mathbb{D}}$ point of the tests was measured. In each patient the duration of the postoperative test was longer than that of the preoperative test. While all the patients had a positive exercise test before the operation, the test was negative in 11 after it. In 10 of these 11 patients the HR and RPP attained at the end point of the postoperative test had increased; the HR and RPP remained unchanged in one patient. Positive tests were still present in seven of the 18 patients. In five of these the HR/ST threshold and RPP/ST threshold were greater after than before operation, and they remained unchanged in two. An improvement in myocardial blood supply after aortocoronary bypass was suggested indirectly by the ability to attain, during exercise, a higher HR and RPP at the end point of the test. The test proved especially valuable in patients who retained a positive exercise test after the operation.

Aortocoronary bypass is widely used in the treatment of coronary artery disease. While it has been shown that the operation is associated with an acceptable rate of graft patency, evidence that it leads consistently to reversal of regional myocardial ischaemia especially in patients with more than one bypass graft has been scarce. ${ }^{12}$ Recently a non-invasive exercise test with an objective end point was used to study the effects of physical training in patients with angina pectoris caused by coronary artery disease. ${ }^{3}$ It was shown that the ability to attain during exercise a greater heart rate and systolic blood pressure at a predetermined level of ischaemic ST segment depression, could

Address for reprint requests: Professor RJ Linden, Department of Cardiovascular Studies, The University of Leeds, Leeds LS2 9JT. be attributed to an improvement in myocardial blood supply. ${ }^{3}$

The present study was planned prospectively to investigate whether, using this method in patients in whom a bypass operation had been performed, $\omega$ there was an improvement in myocardial blood supply.

\section{Subjects and methods}

Nineteen consecutive patients, in whom the diag- $\frac{\vec{\Phi}}{\mathbb{D}}$ nosis of angina pectoris caused by coronary artery disease was established by the ischaemic response $\varrho$ during exercise electrocardiography and by selective coronary arteriography, were investigated before and after aortocoronary bypass. Patients 
with hypertension, valve disease, or cardiac arrhythmia, patients with resectable aneurysm of the left ventricle, and patients who had to be maintained on digoxin, beta-blockers, or nifedipine were excluded from the study. In the 19 patients beta-blocker therapy was stopped under medical supervision during admission to hospital before the operation, for at least five days to allow exercise testing. Critical coronary arterial stenosis, defined as a decrease in the diameter of $75 \%$ or more in one or more of the major vessels was a prerequisite for the operation. The operative technique was identical in all the patients and included extracorporeal circulation before incision of the coronary arteries. Saphenous vein grafts were used to bypass the coronary lesions.

Exercise electrocardiography was performed in all patients the week before and six months after the operation, and the results were analysed without previous knowledge of the extent of the coronary lesions or the details of the operation.

\section{EXERCISE TEST}

The patients attended the laboratory at least two hours after the most recent meal. They were tested on an electrically braked bicycle ergometer (Elema Schonander, type 380). The exercise test consisted of two stages, the first involving continuous exercise and the second discontinuous exercise as previously described. ${ }^{3}$

\section{Continuous test}

In this stage the patients pedalled at $60 \mathrm{rpm}$ against the presented workload, initially $150 \mathrm{kpm} \cdot \mathrm{min}^{-1}$ $(24.5 \mathrm{~W})$, and then stepwise increases at threeminute intervals, each of $150 \mathrm{kpm} \cdot \mathrm{min}^{-1}(24.5 \mathrm{~W})$. Three possible end points of the test were defined: a positive test when the end point was ST segment depression on the ECG recorded from $\mathrm{CM}_{5}$ position; a negative test indicated by the absence of ST segment depression when the patient attained $85 \%$ of age-predicted maximal heart rate response; and an indeterminate test when the exercise had to be terminated because of chest pain, multiple ventricular ectopic beats, or fatigue, and not because of the occurrence of ST segment depression, or because the patient attained the described target in terms of heart rate response. ${ }^{4}$

\section{Discontinuous test}

After 40 minutes rest, patients with positive tests performed a second test in which incremental work loads were separated by rest periods. The initial load was the same as that which initially resulted in the highest heart rate response before the onset of positive ST depression. Subsequent loads were increased stepwise by $25 \mathrm{kpm} \cdot \mathrm{min}^{-1}$ $(4 \cdot 1 \mathrm{~W})$ until the described positive end point of the test. The heart rate (beats. $\mathrm{min}^{-1}$ ) was obtained from the ECG. The systemic blood pressure was measured, using en electronic sphygmomanometer (Elag-Koln), at every workload when the heart rate attained a steady value.

In positive tests, ST segment depression-that is, the end point of the test-was defined as a net ST segment depression of $0.1 \mathrm{mv} 80 \mathrm{~ms}$ after the $\mathrm{J}$ point of the ECG, in the presence or absence of anginal pain. This end point served as the reference level at which the duration of the continuous test was measured. The heart rate (HR) and systolic blood pressure (SBP) at this level of ST segment depression during the discontinuous test were measured to yield the HR/ST threshold and the threshold of the product of HR and SBP (RPP/ST threshold).

In negative tests, the values of HR and RPP attained at the end point of the continuous test were included in the analysis.

\section{Accuracy of measurements}

Adequate reproducibility of the measurement of HR/ST threshold has been previously demonstrated in anginal patients. The 95\% tolerance limit with $95 \%$ confidence of repeated measurement is 2.5 beats. $\min ^{-1}{ }^{3}$

The performance of the electronic sphygmomanometer (Elag-Koln) was validated by comparing it with a random zero sphygmomanometer (Sreeharan and Linden, 1979; unpublished observations). Sixty-six pairs of observations in 11 patients showed that the regression slope did not differ significantly from unity; SBP (Elag-Koln) average data being greater than SBP of the random zero sphygmomanometer by an average of $1 \mathrm{mmHg}(0.133 \mathrm{kPa})$ (SEM $0.65 \mathrm{mmHg}$; 0.086 $\mathrm{kPa}$ ). The random error (two SD) of the difference between duplicate observations was $6.2 \mathrm{mmHg}$ $(0.82 \mathrm{kPa})$ for Elag-Koln and $6.0 \mathrm{mmHg}(0.80 \mathrm{kPa})$ for the random zero sphygmomanometer.

\section{Results}

Nineteen male patients with an average age of 51.8 years (range 38-64 yr) were investigated. Six had a history of myocardial infarction. Details of coronary arteries bypassed are shown in table 1 . All patients survived the operation and none developed a perioperative or postoperative myocardial infarction as assessed by serial electrocardiographic recordings (resting 12 lead 
Table 1 Details of coronary vessels bypassed in 19 patients

\begin{tabular}{lcll}
\hline Coronary artery & \multicolumn{4}{l}{ Number of patients } \\
\cline { 2 - 4 } & One vessel & Two vessels & Three vessels \\
\hline AD & 2 & - & - \\
AD, RCA & - & 7 & - \\
CIRCUM, RCA & - & 4 & - \\
AD, CIRCUM & - & 1 & - \\
AD, CIRCUM, RCA & - & - & 5
\end{tabular}

AD, anterior descending; circum, circumflex; RCA, right coronary artery.

electrocardiogram) and by enzyme studies. At the time of assessment none of the patients was in cardiac failure and no medical therapy had been started. All the patients were managed identically by the same surgical team and without knowledge of the results of exercise tests. At the time of the postoperative exercise tests none of the patients was incapacitated symptomatically. The body weight of each patient was within $8 \%$ of that measured before the operation.

All the patients were tested before and six months after the operation. All patients before operation had a positive result. After operation, seven patients retained a positive result, and 11 patients had a negative result; the test in the remaining patient (19) was indeterminate and was not included in the analysis (table 2).

Table 2 Results of exercise tests in the postoperative period

\begin{tabular}{lccc}
\hline Vessel bypassed & Positive & Negative & $\begin{array}{c}\text { Indetermin- } \\
\text { ate }\end{array}$ \\
\hline AD & 1 & - & 1 \\
AD, RCA & 2 & 5 & - \\
CIRCUM, RCA & 1 & 3 & - \\
AD, CIRCUM & - & 1 & - \\
AD,CIRCUM, RCA & 3 & 2 & - \\
\hline
\end{tabular}

Abbreviations as in table 1 .

Details of the 11 patients in whom the result of the exercise test changed from positive before to negative after operation, are shown in table 3 . In 10 of these, the HR and RPP attained at the end point of the exercise test were greater after operation. Each patient was able to exercise at a higher level of HR and RPP in the later test and in every instance the increase in level of HR attained during exercise exceeded the tolerance limit of measurement. In the remaining patient (16) the changes in HR were within the tolerance limit of measurement and there was a decrease in RPP.
Table 3 Changes in the response to exercise testing in 11 patients in whom the test was negative after the operation

\begin{tabular}{|c|c|c|c|c|c|c|c|c|}
\hline \multirow{2}{*}{$\begin{array}{c}\text { Patient } \\
1\end{array}$} & \multicolumn{2}{|c|}{$\begin{array}{l}\text { End point } \\
\text { angina } \\
\text { before after }\end{array}$} & \multicolumn{2}{|c|}{$\begin{array}{l}\text { End point } \\
\text { heart rate } \\
\text { (beats.min }{ }^{-1} \text { ) } \\
\text { before after }\end{array}$} & \multicolumn{2}{|c|}{$\begin{array}{l}\text { Ent point rate } \\
\text { pressure product } \\
\text { before after }\end{array}$} & \multicolumn{2}{|c|}{$\begin{array}{l}\text { Duration } \\
\text { (min) } \\
\text { before after }\end{array}$} \\
\hline & + & - & 110 & 145 & $165(21 \cdot 9)$ & $203(27 \cdot 0)$ & 8 & 15 \\
\hline 2 & + & - & 130 & 145 & $163(22 \cdot 5)$ & $203(27 \cdot 0)$ & 4 & 13 \\
\hline 3 & + & - & 110 & 150 & $165(21 \cdot 9)$ & $225(29.9)$ & 9 & 15 \\
\hline 4 & + & - & 110 & 140 & $176(23 \cdot 4)$ & $252(33 \cdot 5)$ & $8 \cdot 5$ & 16 \\
\hline 5 & + & - & 118 & 138 & $189(25 \cdot 1)$ & $235(31 \cdot 3)$ & 8 & 12 \\
\hline 6 & + & - & 110 & 135 & $165(21 \cdot 9)$ & $203(27 \cdot 0)$ & 10 & 15 \\
\hline 7 & + & - & 82 & 145 & $98(13.0)$ & $232(30.9)$ & 6 & 15 \\
\hline 8 & + & - & 118 & 140 & $189(25 \cdot 1)$ & $232(30.9)$ & 8 & 12 \\
\hline 9 & + & - & 100 & 135 & $180(23 \cdot 9)$ & $270(25 \cdot 9)$ & 4 & 12 \\
\hline 10 & + & - & 122 & 138 & $210(27 \cdot 9)$ & $235(31 \cdot 3)$ & 12 & 15 \\
\hline 16 & + & - & 143 & 145 & $257(34 \cdot 2)$ & $247(32.9)$ & 9 & 12 \\
\hline
\end{tabular}

*Units of rate pressure product: $\mathrm{mmHg} \cdot \min ^{-1} 10^{2}\left(\mathrm{kPa} \cdot \min ^{-1} 10^{2}\right) ;$ conversion factor $7 \cdot 52$.

+ Anginal pain at the end point.

-No anginal pain at the end point of the exercise.

Considering all the patients in this group, HR $\cong$ increased from an average 113.9 beats. $\min ^{-1}$. (range $82-143$ ) to an average 141.5 beats. min $^{-1}$ (range 135-150), a mean increase of 27.6 beats. $\min ^{-1}(2 \mathrm{p}<0.001$; paired $t$ test $)$. The mean RPP increased from $178.5 \mathrm{mmHg} \cdot \mathrm{min}^{-1} 10^{2}$ (range 98- $\frac{Q}{\mathbb{Q}}$

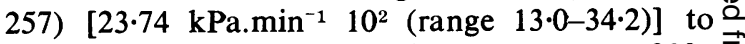
an average $230.6 \mathrm{mmHg} \cdot \mathrm{min}^{-1} 10^{2}$ (range 203- $\overline{\overline{0}}$ $270\left[30.67 \mathrm{kPa} \cdot \mathrm{min}^{-1} 10^{2}\right.$ (range 27.0-35.9)], that is, a mean increase of $52.2 \mathrm{mmHg} \cdot \mathrm{min}^{-1} 10^{2}$ $\left(6.94 \mathrm{kPa} \cdot \mathrm{min}^{-1} 10^{2} ; 2 \mathrm{p}<0.001\right.$; paired $t$ test).

While before operation the end point of the test was always associated with anginal pain, none of these 11 patients experienced anginal pain in the second test. The duration of exercise performed 3 . by each patient was greater in the postoperative $\delta$ than in the preoperative test $(2 \mathrm{p}<0.001$; paired $t$ test).

In seven patients, the result of the exercise test remained positive after the operation-that is, 을 ST segment depression during exercise was retained (table 4). The HR/ST threshold showed $\sigma$ changes which exceeded the tolerance limit of $N$ measurement during sequential exercise testing in $\underset{\omega}{N}$ five patients only. Each patient was able to exercise after operation at a greater HR and RPP at the same level of ischaemic ST segment de- $\frac{\mathbb{C}}{\mathbb{Q}}$ pression compared with the preoperative test. In $\stackrel{\mathcal{Q}}{+}$ the remaining two patients $(17,18)$ the changes in 0 HR/ST threshold were within the tolerance limit $\stackrel{\circ}{\circ}$ of measurement, and the changes in RPP/ST threshold were small. In these seven patients the $\mathbb{Q}$ HR/ST threshold increased from an average 111.30 beats. $\mathrm{min}^{-1}$ (range $94-130$ ) to an average $127 \cdot 0$ beats. $\min ^{-1}$ (range 110-145), a mean increase of 0 
Table 4 Changes in the response to exercise testing in seven patients with a positive test after the operation

\begin{tabular}{|c|c|c|c|c|c|c|c|c|}
\hline \multirow{2}{*}{ Patient } & \multirow{2}{*}{\multicolumn{2}{|c|}{$\begin{array}{l}\text { End point } \\
\text { angina } \\
\text { Before After }\end{array}$}} & \multirow{2}{*}{\multicolumn{2}{|c|}{$\begin{array}{l}\text { End point } \\
\text { heart rate } \\
\text { (beats.min } \text { min }^{-1} \text { ) } \\
\text { Before After }\end{array}$}} & \multicolumn{2}{|c|}{ Rate pressure product } & \multicolumn{2}{|c|}{$\begin{array}{l}\text { Duration } \\
(\min )\end{array}$} \\
\hline & & & & & Before & After & Befo & e After \\
\hline 11 & + & - & 125 & 140 & $213(28 \cdot 3)$ & $238(31 \cdot 7)$ & 4 & 12 \\
\hline 12 & + & - & 94 & 122 & $122(16 \cdot 2)$ & $201(26 \cdot 7)$ & 3 & 12 \\
\hline 13 & + & + & 98 & 130 & $147(19 \cdot 6)$ & $228(30 \cdot 3)$ & 3 & 9 \\
\hline 14 & + & + & 130 & 145 & $221(29 \cdot 4)$ & $247(32.9)$ & 6 & 11 \\
\hline 15 & + & - & 105 & 125 & $168(22 \cdot 3)$ & $188(25.0)$ & 8 & $8 \cdot 5$ \\
\hline 17 & + & - & 115 & 117 & $265(35 \cdot 2)$ & $269(35.8)$ & 6 & 11 \\
\hline 18 & + & - & 112 & 110 & $146(19 \cdot 4)$ & $138(18.4)$ & 5 & 9 \\
\hline
\end{tabular}

Units and abbreviations as in table 3.

15.7 beats. $\min ^{-1}(2 \mathrm{p}<0.002$; paired $t$ test $)$. The $\mathrm{RPP} / \mathrm{ST}$ threshold increased from an average $183 \cdot 1$ $\mathrm{mmHg} \min ^{-1} 10^{2}$ (range 122-265) [24.35 kPa. $\min ^{-1} 10^{2}$ (range $16 \cdot 2-35 \cdot 2$ )] to an average 215.6 mmHg. $\min ^{-1} 10^{2}$ (range 138-269) [28.67 kPa. $\min ^{-1} 10^{2}$ (range $18 \cdot 4-35.8$ ) ] that is a mean increase of $32.4 \mathrm{mmHg} \min ^{-1} 10^{2}\left(4.31 \mathrm{kPa} \cdot \mathrm{min}^{-1}\right.$ $10^{2} ; 2 \mathrm{p}<0.05$; paired $t$ test). While ischaemic ST segment depression was always associated with anginal pain in preoperative tests, only two out of the seven patients experienced anginal pain in postoperative tests. After operation the duration of exercise performed by each patient was longer than before $(2 \mathrm{p}<0.005$; paired $t$ test $)$.

\section{Discussion}

There is widespread concern regarding the lack of unequivocal evidence that aortocoronary bypass effects a relatively long-lasting improvement or prolongs life in patients with symptomatic coronary artery disease in spite of reports of an acceptable incidence of graft patency. ${ }^{12}$ The reported studies on the effectiveness of myocardial revascularisation have shown variable results, partly because of the use of subjective methods and partly because of the difficulty in demonstrating reversal of ischaemia in more than one ischaemic region, especially in patients who retain evidence of myocardial ischaemia after the operation. Qualitatively for instance, the subjective relief of angina pectoris may be brought about by other factors in addition to improvement in the supply of blood to the myocardium-for example, perioperative myocardial infarction, denervation of the ischaemic zone, and a placebo effect. ${ }^{25-7}$

Objective studies on the ability of bypass surgery to improve the supply of blood to the myocardium, have used both invasive and non-invasive techniques.

\section{INVASIVE METHODS}

The results of studies of left ventricular function in terms of segmental contractility, pressure, volume and flow parameters, myocardial blood flow, and regional myocardial perfusion have yielded variable results in respect of sequential improvement or deterioration in a given patient, despite graft patency. ${ }^{8-20}$

Using these methods, especially in patients with more than one bypass graft, it is difficult to determine which coronary lesions are the critical ones in any given patient. Similar difficulties have been experienced in the use of myocardial imaging during exercise; in patients with multi-vessel disease it has been difficult to detect all the disease sites. $^{21}$ For example, a normal scan, at rest and during exercise, does not totally exclude an occluded graft, and a perfusion defect during exercise has been obtained when the grafts were patent. ${ }^{22}$ Thus, from these studies it is possible to conclude that a successful bypass in terms of anatomical patency of the grafts does not necesarily indicate functional improvement in oxygen availability to ischaemic regions of the myocardium, so that the functional effects cannot be predicted.

NON-INVASIVE METHODS

Exercise electrocardiography provides an objective and non-invasive method of provoking ischaemic ST segment depression, ${ }^{4}$ and has potential for the quantitative evaluation of the balance between myocardial oxygen requirement and availability ${ }^{23}{ }^{24}$ It is yet to be demonstrated conclusively that myocardial imaging would provide a more sensitive technique in detecting myocardial ischaemia as compared with exercise electrocardiography. ${ }^{2526} \mathrm{~A}$ recent account of the assessment of aortocoronary bypass using exercise thallium-201 myocardial imaging and exercise electrocardiography suggested that the latter "may be misleading after aortocoronary bypass operation". ${ }^{27}$ However, a symptom-limited exercise test was used, "a target heart rate was not used" and the heart rate response attained by each patient was not given. It is not possible from the data in that report to conclude whether the absence of abnormal electrocardiographic changes during exercise would label the test results negative or indeterminate. Also because the end point of both exercise electrocardiography and exercise imaging was not objectively determined, it is not clear whether both tests were terminated at an intensity sufficient to provoke myocardial ischaemia. For example, after coronary bypass, a positive exercise test was said 
to develop "at heavy work loads" in four patients in whom exercise thallium imaging showed no evidence of ischaemia. Therefore in that report, ${ }^{27}$ it is not possible to compare the results of exercise electrocardiography with those of exercise imaging.

Exercise testing has been used to study the effect of coronary bypass first in terms of improvement in exercise performance - that is, an increase in the duration of exercise and maximal oxygen consumption. It is also used to determine the ability to increase myocardial blood supply-that is, the ability to exercise to a higher heart rate and systolic blood pressure and therefore to a higher myocardial oxygen consumption before angina occurs. ${ }^{28}$ However, it has been recognised that changes in exercise performance can be influenced not only by the effect of revascularisation but by the response of the patient to surgical procedures, ${ }^{29}$ and by the patients' physical activity and conditioning before and after operation. ${ }^{30}$ The use of a subjective sensation such as anginal pain as the end point for a positive response has obvious limitations. It has been shown that sham procedures may influence pain patterns, ${ }^{29}$ and that pain relief can be affected by factors other than myocardial revascularisation. Most of the exercise testing which has been used indirectly to study changes in myocardial blood supply in patients undergoing coronary bypass, has been symptomlimited. ${ }^{7} 913162730^{-39}$

In one report heart rate and systolic blood pressure at the end point of the test were measured during treadmill exercise tests in three groups of patients before and after coronary bypass. ${ }^{40}$ The groups included 10 patients with patent grafts, four patients with "partial revascularisation," and six patients with occluded grafts. The response at ST segment depression of $0.1 \mathrm{mv}$ could be analysed in only 10 patients, seven, one, and two in each group respectively, because of abnormal baseline ECG recordings. All the seven patients with patent grafts had a negative test after the operation; in the remaining three patients who retained a positive test after the operation the heart rate and the heart rate-pressure product responses at ischaemic ST segment depression showed no improvement. However, data on the tolerance limits of measurements of the heart rate and systolic blood pressure were not given. Only a small group of patients coud be investigated. In particular, there was no mention in the report of the problem of whether patients in whom a positive test is retained could have benefited from the operation. ${ }^{40}$ In the face of multiple grafting procedures it is important to demonstrate whether or not improvement in the supply of blood to the myocardium has occurred $\underset{\Rightarrow}{\vec{S}}$ in spite of only "partial revascularisation".

\section{PRESENT STUDY}

In the present study the techniques of Raffo et $a l^{3} \mathrm{~g}$ were used. They measured heart rate and systolic blood pressure attained at a defined level of ischaemic ST depression (HR/ST threshold and $\vec{\omega}$

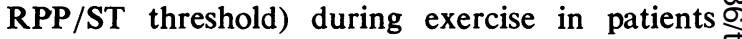
with angina pectoris caused by coronary artery $\vec{x}$ disease. In the present investigation the levels of HR and RPP attained at the end point of exercise tests were assessed in each of 18 patients before $\vec{N}$ and after coronary bypass. In 11 patients a nega- $\infty$ tive exercise test was obtained after the operation, 음 and 10 of these patients attained higher HR and $\overrightarrow{ }$ RPP at the end point of the test after operation. Such results have been interpreted as indicating an $\bar{\varnothing}$ ability to attain a higher level of myocardial $\overrightarrow{0}$ oxygen consumption during exercise, perioper- $\stackrel{\infty}{-}$ ative myocardial infarction having been ex- 0 cluded. ${ }^{2830323440}$ In the present investigation none of the patients developed a perioperative or postoperative myocardial infarction before final exercise testing, and they were therefore considered to $\frac{\otimes}{\circ}$ have shown changes indicating improvement in $\overrightarrow{\vec{D}}$ the supply of blood to the myocardium.

In seven patients, a positive exercise result persisted after the operation. Five of these patients showed an increase in HR/ST threshold and RPP/ ST threshold, indicating an improvement in the ability to exercise to a higher heart rate and systolic blood pressure before the occurrence of the $\frac{0}{0}$ same level of ischaemic ST segment depression. In contrast, the remaining two patients showed no $\delta$ significant change in these thresholds. An increase in these thresholds after a period of physical train-응 ing in patients with ischaemic heart disease has been shown to reflect an increase in myocardialo oxygen consumption at the same level of ischaemic ST segment depression. ${ }^{3}$ Such an increase after ${ }^{\circ}$ aortocoronary bypass indicates improvement in 0 myocardial blood supply. Therefore, these five $\mathrm{C}_{\mathrm{N}}$ patients were considered to have benefited func- tionally, despite retaining evidence of myocardialo ischaemia after the operation.

We conclude that a simple and non-invasive exer $-\stackrel{+}{+}$ cise test can be used to demonstrate indirectly an improvement in the supply of blood to the myocardium in patients who have undergone aorto- $\stackrel{\square}{\square}$ coronary bypass. The technique has been shown@ to be of special value in patients who retain aO positive exercise test after the operation and yeto were improved. 
We are grateful to the British Heart Foundation and the Wellcome Trust for financial support.

\section{References}

1 McIntosh HD, Garcia JA. The first decade of aortocoronary bypass grafting, 1967-1977. A review. Circulation 1978; 57:405-31.

2 Preston TA. Coronary artery surgery: a critical review. New York: Raven Press, 1977.

3 Raffo JA, Luksic IY, Kappagoda CT, Mary DASG, Whitaker W, Linden RJ. The effects of physical training on myocardial ischaemia in patients with coronary artery disease. $\mathrm{Br}$ Heart $\mathrm{J}$ 1980; 43:262-9.

4 Raffo JA, Luksic IY, Kappagoda CT et al. Diagnostic values of routine exercise testing in hospital patients with angina pectoris. $\mathrm{Br}$ Med J 1979; 2:295-7.

5 Benchimal A, Santos AD, Desser KB. Relief of angina pectoris in patients with occluded coronary bypass grafts. Am J Med 1976; 60:339-43.

6 Frick MH. An appraisal of symptom relief after coronary bypass graft. Postgrad Med J 1976; 52: 765-9.

7 Mnayer M, Chahine RA, Raizner AE. Mechanisms of angina relief in patients with coronary artery bypass surgery. Br Heart $J$ 1977; 39:605-9.

8 Amsterdam EA, Hughes JL, DeMaria AN, Zelis $\mathbf{R}$, Mason DT. Indirect assessment of myocardial oxygen consumption in the evaluation of mechanisms and therapy of angina pectoris. $A m J$ Cardiol 1974; 33:737-43.

9 Barry WH, Pfeifer JF, Lipton MJ, Tilkian AG, Hultgren Hn. Effects of coronary artery bypass grafting on resting and exercise hemodynamics in patients with stable angina pectoris: a prospective, randomized study. Am J Cardiol 1976; 37:823-30.

10 Chatterjee K, Swan HJC, Parmley WW, Sustaita H, Marcus HS, Matloff J. Influence of direct myocardial revascularization of left ventricular asynergy and function in patients with coronary heart disease. Circulation 1973; 47:276-86.

11 Chatterjee K, Matloff JM, Swan HJC et al. Improved angina threshold and coronary reserve following direct myocardial revascularization. $C i r$ culation 1975; 51-52:suppl 1, 81-91.

12 Griffith LSC, Achuff SC, Conti CR et al. Changes in intrinsic coronary circulation and segmental ventricular motion after saphenous-vein coronary bypass graft surgery. $N$ Engl J Med 1973; 288: 589-95.

13 Hammermeister KE, Kennedy JW, Hamilton GW, Stewart DK, Gould KL, Lipscomb K, Murray JA. Aortocoronary saphenous-vein bypass: failure of successful grafting to improve resting left ventricular function in chronic angina. N Engl J Med 1974; 290:186-92.

14 Kloster FE, Kremkau EL, Rahimtoola SH et al.
Prospective randomized study of coronary bypass surgery for chronic stable angina. Cardiovasc Clin 1977; 8:145-56.

15 Kolibash AJ, Goodenow JS, Bush CA, Tetalman MR, Lewis RP. Improvement of myocardial perfusion and left ventricular function after coronary artery bypass grafting in patients with unstable angina. Circulation 1979; 59:66-74.

16 Lapin ES, Murray JA, Bruce RA, Winterscheid L. Changes in maximal exercise performance in the evaluation of saphenous vein bypass surgery. $\mathrm{Cir}$ culation 1973; 47:1164-73.

17 Manley JC, Johnson WD, Flemma RJ, Lepley D. Objective evaluation of the effect of direct myocardial revascularization on ventricular performance utilizing submaximal ergometer exercise testing. Am J Cardiol 1972; 29:277.

18 Shepherd RL, Itscoitz SB, Glancy DL et al. Deterioration of myocardial function following aorto-coronary bypass operation. Circulation 1974; 49:467-75.

19 Wolf NM, Kreulen TH, Bove AA et al. Left ventricular function following coronary bypass surgery. Circulation 1978; 58:63-70.

20 Zeft HJ, Manley JC, Huston JH, Tector AJ, Auer JE, Johnson WD. Left main coronary artery stenosis. Results of coronary bypass surgery. Circulation 1974; 49:68-76.

21 Strauss $\mathrm{HW}$, Pitt B. Evaluation of cardiac function and structure with radioactive tracer techniques. Circulation 1978; 57:645-54.

22 Kolibash AJ, Thomas DC, Bush CA, Tetalman MR, Lewis RP. Myocardial perfusion as an indicator of graft patency after coronary artery bypass surgery. Circulation 1980; 61:882-7.

23 Clausen JP. Circulatory adjustments to dynamic exercise and effect of physical training in normal subjects and in patients with coronary artery disease. Progr Cardiovasc Dis 1976; 18:459-95.

24 Fortuin NJ, Weiss JL. Exercise stress testing. Circulation 1972; 56:699-712.

25 Bailey IK, Griffith LSC, Rouleau J, Strauss HW, Pitt B. Thallium-201 myocardial perfusion imaging at rest and during exercise. Comparative sensitivity to electrocardiography in coronary artery disease. Circulation 1977; 55:79-87.

26 McGowan RL, Martin ND, Zaret BL et al. Diagnostic accuracy of noninvesive myocardial imaging for coronary artery disease: an electrocardiographic and aniographic correlation. Am J Cardiol 1977; 40:6-10.

27 Robinson PS, Williams BT, Webb-Peploe MM, Crowther A, Coltart DJ. Thallium-201 myocardial imaging in assessment of results of aortocoronary bypass surgery. Br Heart J 1979; 42:455-62.

28 Ellestad MH, Cooke BM, Greenberg PS. Stress testing: clinical application and predictive capacity. Progr Cardiovasc Dis 1979; 21:431-60.

29 Dimond EG, Kittle CF, Crockett JE. Comparison of internal mammary artery ligation and sham- 
operation for angina pectoris. Am J Cardiol 1960; 5:483-6.

30 Bartel AG, Behar VS, Peter RH, Orgain ES, Kong Y. Exercise stress testing in evaluation of aortocoronary bypass surgery. Circulation 1973; 48:141-8.

31 Aronow WS, Stemmer EA. Two-year follow-up of angina pectoris: medical or surgical therapy. $A n n$ Intern Med 1975; 82:208-12.

32 Block TA, Murray JA, English MT. Improvement in exercise performance after unsuccessful myocardial revascularization. Am J Cardiol 1977; 40:673-80.

33 Frick MH, Harjola PT, Valle M. Effect of aortocoronary grafts and native vessel patency on the occurrence of angina pectoris after coronary bypass surgery. Br Heart $J$ 1975; 37:414-9.

34 Guiney TE, Rubenstein JJ, Sanders CA, Mundth ED. Functional evaluation of coronary bypass surgery by exercise testing and oxygen consumption. Circulation 1973; 47-48: suppl III, 141-5.

35 Mathur VS, Guinn GA, Anastassiades LC et al. Surgical treatment for stable angina pectoris.
Prospective randomized study. N Engl $J$ Med 1975; 292:709-13.

36 Merrill AJ, Thomas C, Schechter E, Cline R, 흘 Armstrong R, Stanford W. Coronary bypass? surgery, value of maximal exercise testing in $\mathbb{\complement}$ assessment of results. Circulation 1975; 51-52:0 suppl I, 173-7.

37 Nitter-Hauge S. Exercise ECG in evaluation of: aortocoronary bypass surgery. Report on $66 \overrightarrow{\vec{\omega}}$ patients. Europ J Cardiol 1979; 9:191-8.

38 Selden R, Neill WA, Ritzmann LW, Okies JE, Anderson RP. Medical versus surgical therapyx for acute coronary insufficiency. A randomized study. N Engl J Med 1975; 293:1329-33.

39 Siegel W, Lim JS, Proudfit WL, Sheldon WC, Loop FD. The spectrum of exercise test and an- $-\infty$ giographic correlations in myocardial revascular-윽 ization surgery. Circulation 1974; 51-52:suppl I,, $156-61$.

40 Knoebel SB, McHenry PL, Phillips JF, Lowe DK. The effect of aortocoronary bypass grafts on myocardial blood flow reserve and treadmill exercise ${ }_{\infty}^{\circ}$ tolerance. Circulation 1974; 50:685-93. 